\title{
Ultrasonic Vibration Reaming Processing Technology Research on 45 Steel
}

\author{
Xiao-feng $\mathrm{XU}^{1, \mathrm{a}^{*} \text {, Chao-Xun } \mathrm{ZHOU}}{ }^{2, \mathrm{~b}}$ \\ ${ }^{1}$ Key laboratory of wood science and technology, Zhejiang Agriculture and Forestry University, \\ Lin'an 311300, Zhejiang Province, China \\ ${ }^{2}$ Zhijiang College of Zhejiang University of Technology, Hangzhou 310024,Zhejiang Province, \\ China \\ axxf@zafu.edu.cn, bcxj0577@163.com
}

\begin{abstract}
Keywords: ultrasonic vibration, reaming, surface roughness, circular degree
Abstract: This paper adopts the ultrasonic vibration reaming, whereas reamer dry type implements the separation of the pulse function type vibration cutting and eliminates the ordinary cutting process of elastic vibration extrusion a regular pulse intermittent cutting process was achieved by which the cutting force was reduced to normal cutting for anywhere between a third and one over ten. The process improved the surface quality and machining precision. At the same time, the effects of cutting speed, feed and ream allowance were investigated for influence of reaming on the surface roughness and circular degree in this paper. Experimental data show that the surface roughness and circular degree by ultrasonic vibration dry reaming can reach or exceed the grinding effect.
\end{abstract}

\section{Introduction}

With the rapid development of science and technology, especially in the aerospace, electronics, instruments and meters, precision machinery, automatic control and medical equipment, etc., the machining precision demand on the tiny hole is higher and higher, and the processing difficulty is constantly improved as well. The processing technology of the traditional cutting is difficult to eliminate heat because of the high cutting temperature in cutting area, poor rigidity and centering difficulty. Therefore, machining efficiency is low with poor quality and high cost. Many scholars began to improve the cutting condition and the cutting level from the cutting tool, machine tool, cutting fluid, and many other aspects. But the cutting force and cutting heat have not been reduced in essence. In recent years, the modern processing technology was combined with traditional process and some new processing method have been developed from which ultrasonic vibration cutting technology solved the problem of the small hole machining well ${ }^{[1-2]}$.

Reaming is one of the machining methods to produce precision holes. However, when ordinary reaming, reamer and extrusion of hole wall is serious since high temperature in the cutting area, cutting torque, tool life and machining quality are greatly affected. Even in the coolant are adopted to decrease the cutting temperature in the processing, surface roughness and the tool life is still not ideal. Ultrasonic vibration reaming, reamer dry type was adopted to realize the separation of the pulse function type vibration cutting, to improve the surface quality and machining precision of the larger.

\section{Materials and methods}

Ultrasonic vibration reaming. Ultrasonic energy is imposed on reamer by acoustics system and makes it vibrate torsionally at a certain ultrasonic frequency and amplitude of circumferential direction. The acoustic system is installed on the C618K lathe as a vibration reaming system. The schematic diagram is shown in Fig.1. 


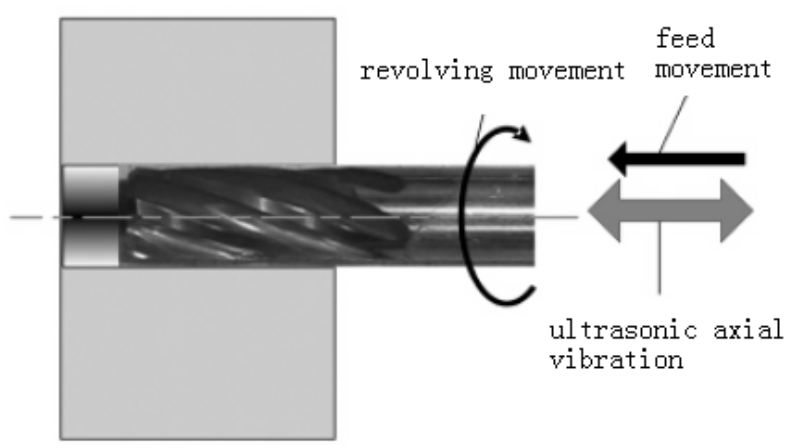

Fig. 1 Vibration ream mechanism analysis

Cutting tool begins to vibrate at a certain vibration amplitude and frequency and form separated type pulse force of vibration cutting to eliminate the ordinary cutting process of elastic vibration extrusion. A regular pulse intermittent cutting process of cutting ,by which the cutting force reduces for anywhere between a third and one over ten for ordinary cutting suitable for cutting temperature close to room temperature, by which the system stability and rigidity are improved.

Ultrasonic generator output power is $0-500 \mathrm{w}$ with $16-23 \mathrm{kHz}$ frequency and the automatic frequency tracking performance.

The common and structural reform cutting tools and reamer were used. In the cutting part of the nodal point grinding certain width, the diameter is less than the cutting part cutting will not be involved.

Experiment materials: 45 steel (HBS180-220), 30CrMnSiA (quenched and tempered).System vibration state: the vibration frequency $\mathrm{f}=20.7 \mathrm{kHz}$, a fixed amplitude, water droplets atomized.

Peculiar phenomena of ultrasonic vibration reaming process. The chips by ultrasonic vibration dry reaming test are like spring filaments. They are thin and long, uniform with good toughness, and they are also not easy to be broken and have basically the same color with the work-piece. The interface of the chips and the cutting tool rake face is very sheeny and smooth.

The surface by ultrasonic vibration dry reaming is pale and covered with uniform mesh case grain which is faced to the letters. The letters on the side wall is clearly visible and there is no ordinary reaming extrusion notch.

Under the condition of experiment when reaming, "giggle" will be heard regularly. The built-up edge has not found in the process of test and the blade is always very smooth and sharp. What's more, the machining surface is without scales.

Cutting temperature has not apparent temperature rise in the process of test. When the work-piece is taken up, it doesn't burn hands. It is thus clear that ultrasonic vibration cutting heat is tiny and dry type reaming cutter wear is very tiny as well.

\section{Results}

Machining accuracy. Ream 45 steel( HBS180-220) and 30CrMnSiA by quenching and tempering. The diameter and length of the specimen are $\Phi 16 \mathrm{~mm}$ and $60 \mathrm{~mm}$ respectively. The outer diameter of the specimen is $\Phi 10 \mathrm{~mm}$ and the bore diameter of the reamed hole is $\Phi 10 \mathrm{~mm}$. Under the condition of the speed $n=292 \mathrm{r} / \mathrm{min}$, feed $\mathrm{s}=0.1 \mathrm{~mm} / \mathrm{r}$, bilateral reaming allowance $0.3 \mathrm{~mm}$, as a set of three specimens are carried out, take its measure the average, the results are shown in table 1.Experimental data show that ultrasonic vibration dry reaming can reach even exceed the grinding effect ${ }^{[3]}$. 


\begin{tabular}{|c|c|c|}
\hline Material & Circular degree $[\mathrm{mm}]$ & Cylindricity $[\mathrm{mm}]$ \\
\hline 45 steel (HBS180-220) & 0.004 & 0.005 \\
\hline 30CrMnSiA (hardened and tempered) & 0.050 & 0.045 \\
\hline
\end{tabular}

Table 1 Machining precision

Effects of surface roughness on reaming process. In the test the specimen's surface roughness are measured by using a contourgraph. The results are shown in table 2 .

\begin{tabular}{|c|c|}
\hline Material & Surface roughness $\mathrm{Ra}[\mu \mathrm{m}]$ \\
\hline 45 steel (HBS180-220) & 0.17 \\
\hline 30CrMnSiA (hardened and tempered) & 0.30 \\
\hline
\end{tabular}

Table 2 Ultrasonic vibration reaming dry surface roughness

The relationship between the surface roughness and cutting speed. The relation curve between the surface roughness $\mathrm{Ra}$ and cutting speed $v$ under the test condition is shown in Fig. 2. It shows that when the cutting speed is less than a certain cutting speed $v \mathrm{c}$, the surface roughness is almost nothing to do with cutting speed. While cutting speed is higher thanvc, surface roughness has no difference as common reaming. So significant effect of ultrasonic vibration reaming will be obtained only the cutting speed must be lower than $v c(v \mathrm{c}=\mathrm{a} \omega)$ and $v \leq 1 / 3 v \mathrm{c}$ when dry type ultrasonic vibration reaming.

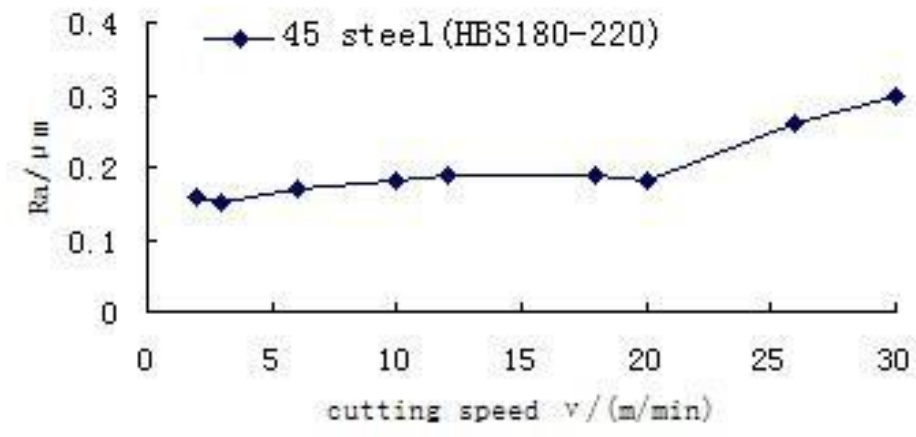

Fig. 2 The influence of cutting speed on surface roughness

$$
a_{p}=0.1 \mathrm{~mm} \text { （unilateral）; } s=0.1 \mathrm{~mm} / \mathrm{r}
$$

The relationship between the surface roughness and the cutting feed. The changing curve between the surface roughness $\mathrm{Ra}$ and the cutting feed ap under the test condition is shown in Fig.3. It shows that in the process of dry type ultrasonic vibration reaming, the cutting feed has a certain relationship with the surface roughness. When the cutting feed increases the surface roughness increases slightly. This is because the reamer is along the main cutting direction vibration in cutting process, rather than along the main cutting motion and feed motion synthesis direction vibration, feeding the greater the impact, the more prominent. Feed movement of the cutting is not fully pulse.

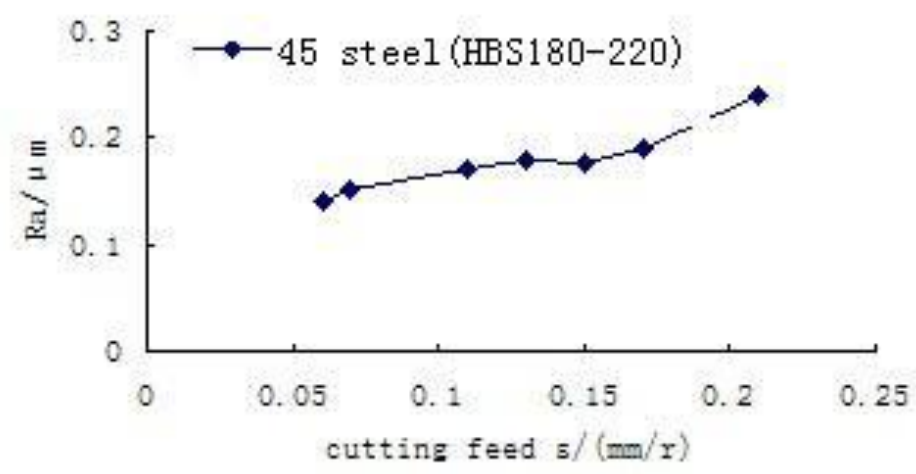

Fig. 3 The influence of cutting feed on surface roughness $a_{p}=0.1 \mathrm{~mm}$ （unilateral）; $v=9.1 \mathrm{~m} / \mathrm{min}$

The relationship between the surface roughness and the depth of the ream. The relation curve between the surface roughness Ra and the depth of the ream ap under the test condition is shown in 
Fig.4. It shows that with the increase of the depth of the ream, the surface roughness will change a little when in ultrasonic vibration dry type reaming. But if the depth is too small, the cutting edge of cold work hardening of the machined surface in the last layer is given priority to the extrusion. The cutting effect will be affected. If the depth is too big, the equivalent mass of cutting tool will be increased and the resonance frequencies of the system will be changed. It will affect the reaming effect as well.

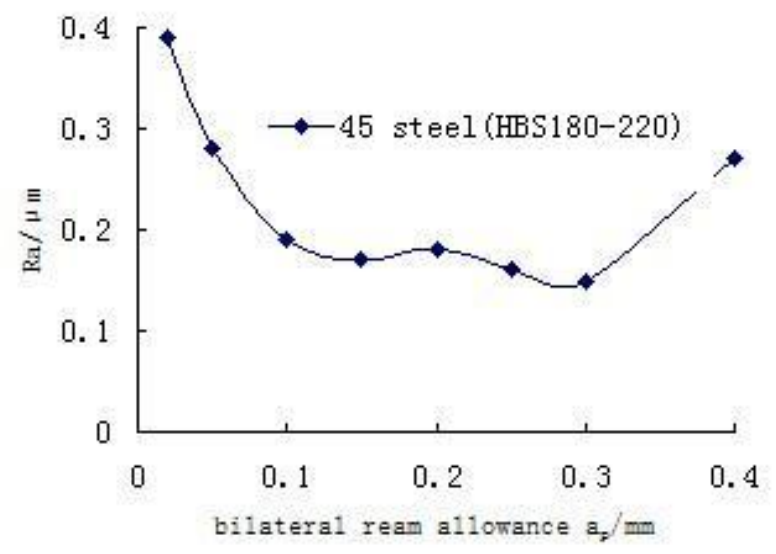

Fig. 4 The influence of ream allowance on surface roughness $\nu=9.1 \mathrm{~m} / \mathrm{min} ; s=0.1 \mathrm{~mm} / \mathrm{r}$

Effect of circular degree on cutting parameters. The circular degree of the processing part is one of the important indexes of machining accuracy. The traditional view is that the index depends largely on the rotating precision of machine tools. But high precision parts will be obtained while dry type ultrasonic vibration reaming on the ordinary machine tools. Fig.5-7 are the relationship curves between the circular degree and the cutting parameters under the above conditions.

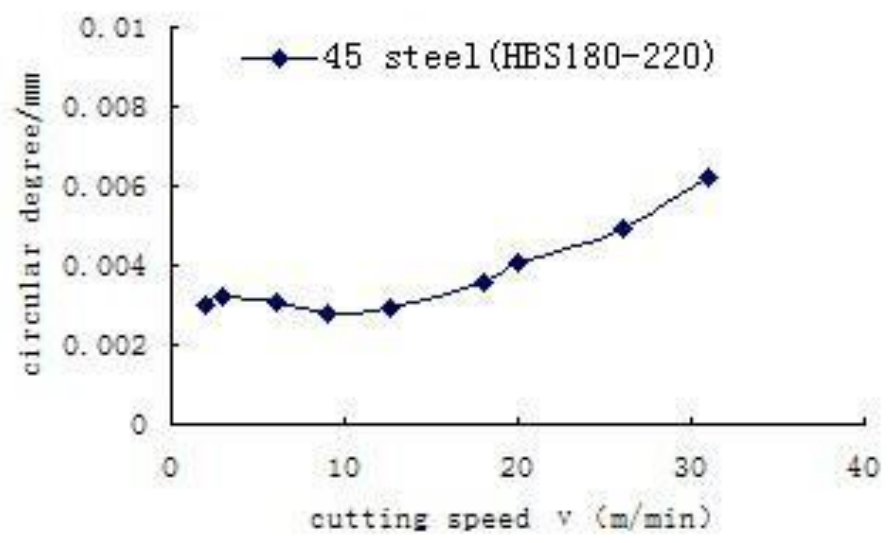

Fig. 5 The influence of cutting speed on the circular degree

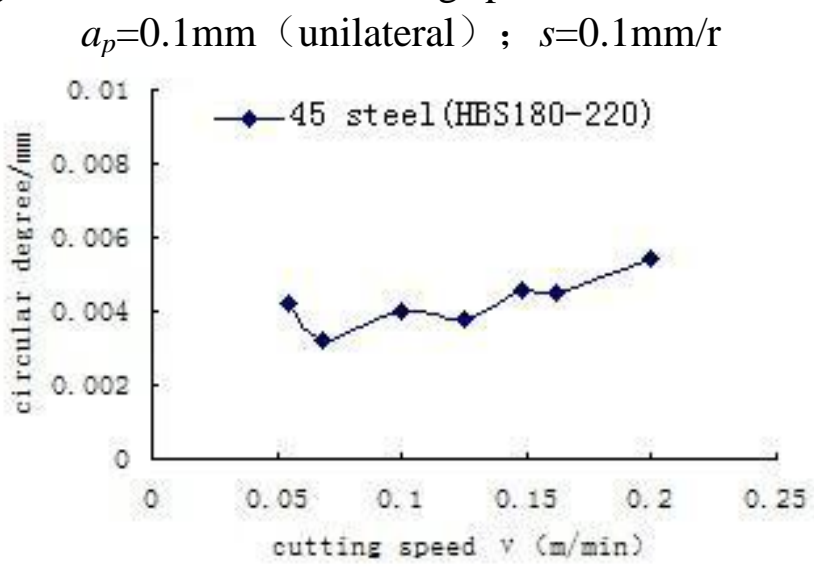

Fig. 6 The influence of cutting feed on the circular degree

$$
a_{p}=0.1 \mathrm{~mm} \text { (unilateral ); } v=9.1 \mathrm{~m} / \mathrm{min}
$$




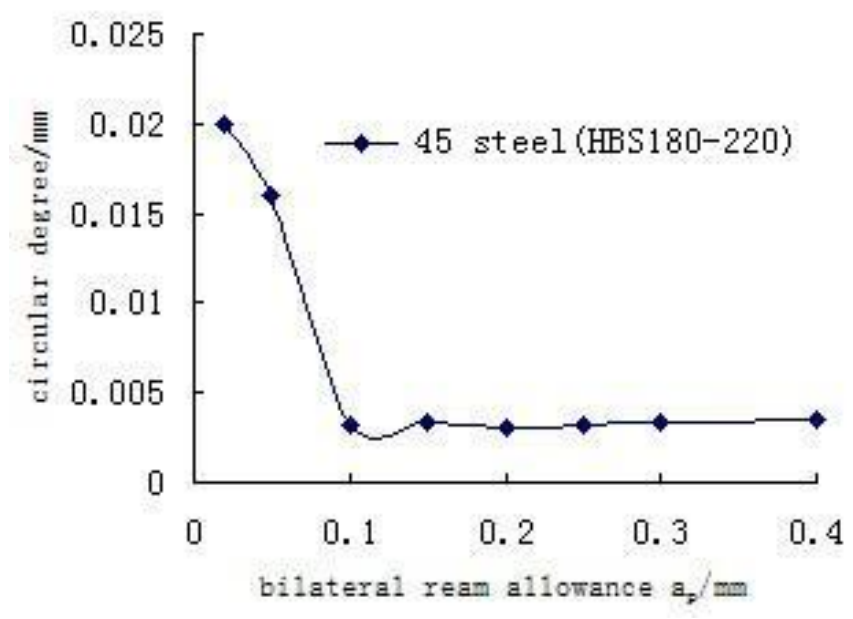

Fig. 7 The influence of ream allowance on the circular degree $v=9.1 \mathrm{~m} / \mathrm{min} ; s=0.1 \mathrm{~mm} / \mathrm{r}$

\section{Discussion}

The curves show that cutting parameters' influence on the circular degree is not big when ultrasonic vibration dry reaming. With the increase of the cutting speed and the cutting feed, the circular degree of the work-piece increased slightly. With the increase of ream allowance, the circular degree of the work-piece will gradually reduce and it tends to be stable when the ream allowance is $0.1 \mathrm{~mm}$.

Although the cutting temperature is very low, the cutting area will get good lubrication if moderate liquid coolant is added in the test. Maybe the surface quality and machining precision of the hole have been further improved. Meanwhile, the reamer wear can be reduced drastically and the service life of the cutting tools can be further improved as well.

\section{Conclusions}

The surface quality and machining precision of the hole have been improved dramatically by ultrasonic vibration reaming processing technology. At the same time, cutting force and cutting temperature has reduced correspondingly. Experimental data show that the surface roughness and circular degree by ultrasonic vibration dry reaming can reach or exceed the grinding effect.

\section{Acknowledgements}

The research was financially supported by the key laboratory of wood science and technology, Zhejiang Province.The author is very thankful to Wood Plastic Composite Ultrasonic Welding Technology Research numbered 2012FK027 by Zhejiang Agriculture and Forestry University and Study on the Mechanism of Ultrasonic Welding of Profiled Wood Plastic Composite Materials numbered Y201430635 by Department of Education of Zhejiang Province for supporting this research.

\section{References}

[1] MU Li, ZHANG Liao-yuan. Ultrasonic Vibration Drilling of Micropore,J. Machinery Design \& Manufacture.2002(6) 51-59.

[2] Chandra Nath,M. Rahman. Effect of Machining Parameters in Ultrasonic Vibration Cutting,J. International Journal of Machine Tools and Manufacture. 2008 (9) 79-84.

[3] D.E.Brehl,T.A.Dow. Review of Vibration-assisted Machining,J. Precision Engineering.2007 (3) 281-304. 